\title{
Kernos
}

Revue internationale et pluridisciplinaire de religion grecque antique

$10 \mid 1997$

Varia

\section{PIÉRART, G. TOUCHAIS, Argos}

\section{Vinciane Pirenne-Delforge}

\section{(2) OpenEdition}

\section{Journals}

Édition électronique

URL : http://journals.openedition.org/kernos/691

DOI : 10.4000/kernos.691

ISSN : 2034-7871

Éditeur

Centre international d'étude de la religion grecque antique

Édition imprimée

Date de publication : 1 janvier 1997

Pagination : 361-362

ISSN : 0776-3824

Référence électronique

Vinciane Pirenne-Delforge, « M. PIÉRARt, G. touchals, Argos », Kernos [En ligne], 10 | 1997, mis en ligne le 12 avril 2011, consulté le 24 septembre 2020. URL : http://journals.openedition.org/kernos/691 ; DOI : https://doi.org/10.4000/kernos.691 
l'écriture, et d'afficher ainsi leur existence sur le plan social à une époque où politiquement cette existence ne leur était pas reconnue. Et ce n'est sans doute pas un hasard si les graffiti sur les offrandes de ces sanctuaires disparaissent, comme le souligne l'A., au début du $\mathrm{VI}^{\mathrm{e}}$ siècle, à l'époque même où l'« écriture » de la loi par Solon résout partiellement du moins les problèmes posés par une justice jusque-là aristocratique, assurant ainsi aux kakoi le statut des bomoioi qui était le leur dans l'armée, sans l'être dans la cité. Ici, plus peut-être que dans l'évolution des rites funéraires, on voit se dessiner une corrélation étroite entre le religieux, le social et le politique.

C'est cette même corrélation que l'on peut établir, me semble-t-il, si l'on estime que sur l'Agora d'Athènes les premières fondations qui remontent à Solon sont celles d'un Bouleutèrion-Mètrôon qui continuera à y exister jusqu'à la fin de l'antiquité, en association avec l'usage de l'écriture dans la vie politique, puisqu'à Athènes, le Mêtrôon était centre des archives civiques. Dans son étude sur les origines de l'Agora qui clôt les Actes de ce colloque, J. MCK. CAMP II développe cependant l'idée d'une fonction d'abord athlétique et sportive pour le site, la découverte en 1980 d'une piste dont le départ se trouvait à l'Est de l'autel des Douze dieux l'amenant à voir dans le vaste espace dégagé situé à l'Est du Colonos Agoraios un terrain d'entraînement à la fois sportif et militaire. Mais ici encore la présence d'un autel aux Douze Olympiens, fils d'une Mère olympienne, imprime sa marque au site et en ramène, je pense, les origines à Solon. Des inscriptions des premiers siècles de notre ère témoignent d'ailleurs des liens qui, à Athènes, unissent encore à cette époque les éphèbes à la Mère.

On regrettera dans ce colloque par ailleurs si riche l'absence de la publication de l'étude de M. STAHL sur l'Eunomie solonienne qui aurait pu montrer l'importance de la pensée politique de Solon pour façonner cet idéal politique qui, à Athènes, consista à faire partager par le dèmos des valeurs jusque-là aristocratiques. L'étude des épitaphes versifiées par C. SAERENS montre cependant que, dans l'Athènes du $\mathrm{VI}^{\mathrm{e}}$ siècle, la poésie est perçue comme source de pérennité.

Louise-Marie L'Homme-Wéry

(Université de Liège)

\section{Marcel Piérart, Gilles Touchais, Argos. Une ville grecque de 6000 ans,} Paris-Méditerranée, CNRS Éditions, 1996, 127 p., nbr. ill., plans, cartes (Patrimoine de la Méditerranée). ISBN : 2-271-054222-2.

Célèbre et mal connue, telle se présente Argos, en une formulation paradoxale qui, à elle seule, suffirait à justifier l'ample parcours des auteurs à travers six millénaires d'histoire. Le déséquilibre entre l'étendue de la période prise en compte et les modestes dimensions du volume pourrait paraître problématique : ces craintes sont injustifiées lorsqu'on en mesure la clarté, le caractère didactique et le souci constant d'offrir le dernier état des connaissances sur Argos, en faisant la part de l'hypothèse, sans pour autant verser dans des polémiques de spécialistes. En douze chapitres bien équilibrés, c'est toute l'histoire d'Argos qui déroule sa trame, depuis le temps des héros jusqu'à nos jours. Illustrations et plans ne font pas qu'agrémenter la lecture : ils la nourrissent par la présentation d'objets inédits et par des reconstitutions en élévation. La perspective adoptée est résolument événementielle, ce qui donne aux époques classique et hellénistique de cette histoire de la cité la dimension d'une fresque guerrière. Au cour d'enjeux qu'elle maîtrise ou qui la dépassent, Argos est bien cette «ville grecque 
moyenne ", un exemple qui donne une bonne idée de ce que fut la « cité antique ". De la très haute vulgarisation assurément.

Vinciane PIRENNE-DELFORGE

(Université de Liège)

Jean-Luc LAMBoleY, Les Grecs d'Occident. La période archä̈que, Paris, Sedes, 1996. 1 vol. $11,5 \times 18,5 \mathrm{~cm}, 344$ p., 7 cartes, 18 plans, 10 planches (Regards sur l'bistoire. Histoire ancienne, 111). ISBN : 2-7181-9344-1.

La parution ces derniers mois, dans le cadre du concours de l'Agrégation, de plusieurs ouvrages en français consacrés à la Grèce archaïque a pour heureuse conséquence d'attirer l'attention sur un certain nombre de problématiques qui, en dépit de l'intérêt qui leur avait été porté par d'éminents savants, étaient plutôt restées jusqu'à présent l'affaire des seuls spécialistes. Cela vaut en particulier pour l'histoire de l'Occident grec à laquelle est consacré le présent opuscule. D'emblée son A. annonce son intention de réagir à une certaine forme d'« égéocentrisme » des manuels où l'Occident n'apparaît guère qu'au moment des mouvements de colonisation.

Une introduction succincte pose les problèmes de chronologie, présente les sources littéraires (d'Hérodote à Stéphane de Byzance) sur les difficultés d'utilisation desquelles l'A. insiste, explique l'apport essentiel des sources archéologiques à notre connaissance et termine sur l'idée, qui servira de fil directeur à l'ouvrage, d' « unité et diversité des Grecs d'Occident ». Le premier chapitre (Les terres et les bommes, p. 1951) est consacré pour l'essentiel à une description de la Sicile et de la Grande-Grèce telles que les Grecs purent les découvrir au moment de s'y établir ainsi qu'à l'image que nous en ont donnée les Anciens. Dans le chapitre suivant (L'arrivée des Grecs, p. 5393) est proposé un panorama de la colonisation, l'A. passant en revue les différents sites où se sont installés les colons grecs, présentation qui se fait selon l'ordre chronologique et en fonction de l'origine des arrivants. Le chapitre III (Les Grecs en ExtrêmeOccident, p. 95-143) s'intéresse à l'Extrême-Occident, sans que l'A. propose cette fois une introduction géographique comparable à celle qu'on trouve pour les deux régions prises en compte précédemment. $\mathrm{Y}$ sont aussi rassemblées les conclusions de ce chapitre et du précédent ainsi que des annexes, dont une qui consiste en une série de fiches sur chacune des colonies classées par ordre alphabétique. Dans le chapitre IV (Modes d'occupation du territoire et urbanisme, p. 145-175) sont exposés en détail plusieurs exemples d'organisation du territoire (Tarente, Métaponte, Poseidonia, Siris, Locres) et deux d'urbanisme (Mégara Hyblaea et Sélinonte). Le chapitre V (L'évolution politique et sociale, p. 177-211) décrit les «événements » jugés majeurs pour le $\mathrm{VI}^{\mathrm{e}}$ siècle et le début du $\mathrm{V}^{\mathbf{e}}$, à savoir l'apparition des régimes tyranniques, l'arrivée des Grecs d'Asie Mineure, les conflits entre cités, la constitution des États de Sybaris et de Syracuse et l'apparition du monnayage avant de s'arrêter sur deux « moments » de cette histoire, la chute de Sybaris en 510 et l'apogée de Gélon avec la victoire d'Himère en 480. Le chapitre VI (Le monnayage des cités, p. 213-238) met en avant les enseignements que l'on peut tirer de l'étude des monnaies émises en Grande-Grèce et en Sicile entre les années 540 et le début de la période classique. Les deux derniers chapitres exposent deux aspects de la vie culturelle (VII. Les productions littéraires, p. 239-269; VIII. Les productions artistiques, p. 271-316). 